\title{
Priscol in the Prevention and Management of Leprotic Lagophthalmos
}

\author{
Dr. H. V. NEMA, M.s. \\ Reader in Ophthalmology
}

\author{
DR. J. S. MATHUR, M.D.(MED.), M.D.(S.P.M.), D.P.H.(LOND.), F.R.I.P.H.H.(LOND.) \\ Reader in Social and Preventive Medicine, College of Medical Sciences, \\ Banaras Hindu University, Varanasi, India
}

Lagophthalmos is not an uncommon ocular complication of leprosy. It of ten poses a serious threat to the eye on account of the exposure and accompanied corneal anaesthesia. Incomplete closure of the lids invariably leads to keratitis, corneal ulceration and ultimate blindness.

The incidence of lagophthalmos in leprosy varies in different types of the disease and from country to country. Loutfley (1937) reported $17 \%$ incidence of lagophthalmos in sanatorium patients in Egypt. Doul's (1959) analysis of 202 patients in Hynkyns gave a figure of $5 \%$ and $11 \%$ for tuberculoid and lepromatous types respectively. In our leprosy patients the incidence of lagophthalmos seems to be approximately $3 \%$, a figure significantly lower than the earlier reports. But considering the high incidence of the corneal complications associated with leprotic lagophthalmos, its early correction should be considered necessary.

Presently, the popular mode of treatment of lagophthalmos of any etiology has been tarsorraphy of the outer canthus. In more severe cases tarsorraphies of both the canthi have been practised. Although these procedures successfully prevent the exposure keratitis, they functionally and cosmetically give poor results.

Glazenow (1955) suggested the introduction of fascia lata graft in the lower lid with the object of giving better function and cosmetic results. Such an operation does not impart any movement to the upper lid. Gills and Millard (1957) described temporalis transplant as a suitable procedure for obtaining lid closure in lagophthalmos. Subsequently many workers reported encouraging results with this technique, but due to intricacies in the operation the technique is not popularised.

Therefore, it seems that none of the available techniques for the management of lagophthalmos is ideal. There is a vital need for the newer methods of treatment of lagophthalmos caused by peripheral facial palsy specially of leprotic origin. Recently, Mathur and Saxena (1965), Mathur (1965) and Mathur et al. (1966) reported good response by intraneural priscol in the treatment of leprosy deformities. Encouraged by their observations, we have used priscol in the management of leprotic lagophthalmos. The present report covers our preliminary observation on this aspect.

\section{CASE REPORT}

R.R., male, aged 32 years, attended the Bhowalka Eye Hospital, Banaras Hindu University, Varanasi, with the complaint of inability to close the left eye for the past 7 years. $\mathrm{He}$ was a leprosy patient for the last 18 years and had been receiving anti-leprosy treatment for the last 8 years.

On Examination: The left palpebral aperture was wider and the eye was prominent. Patient had infra-nuclear type of facial paralysis on the left side resulting in ectropion of the left lower lid and marked lagophthalmos (Fig. 1). The left eye had mild conjunctivitis and the left cornea had a faint cresentic opacity near the inferior limbus. The corneal sensation was slightly impaired. The other structures of the eye were normal. The right eye had no ab- 


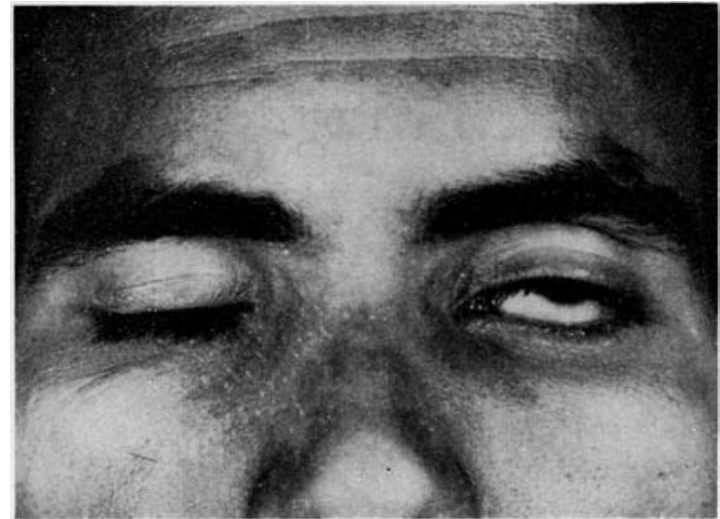

FIG. la

Showing wide left palpebral aperture with slight ectropion of the left lower lid.

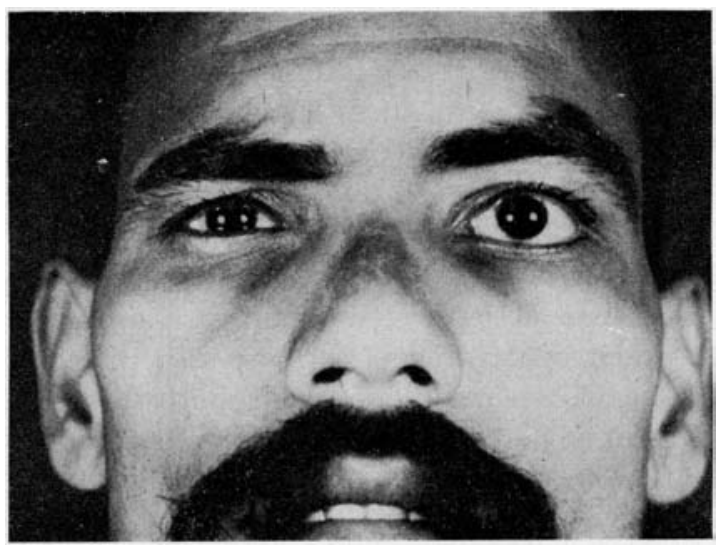

FIG. $1 b$

Showing lagophthalmos of the left eye.

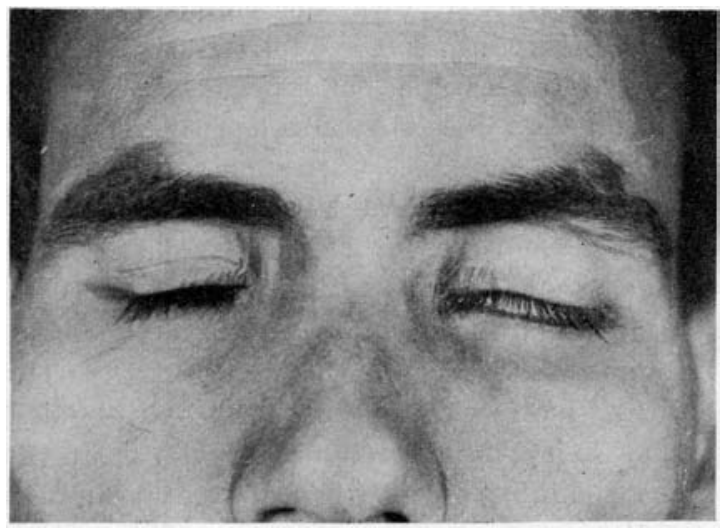

FIG. 2

Showing residual lagophthalmos after priscol therapy. normality. Besides these ocular anomalies, he had loss of sensation, deformities and contracture of all the fingers of both the hands which showed improvement on local intraneural priscol therapy.

He was given a weekly injection of priscol $1 \mathrm{ml}$. by the following technique: Localisation of temperomandibular joint was done by asking the patient to open his mouth. A point $1 \mathrm{~cm}$. below the position of the condyle was selected and with the help of a stout needle $4 \mathrm{~cm}$. long, $0.5 \mathrm{ml}$. of priscol was injected. The needle was then directed and moved $1.5 \mathrm{~cm}$. towards the stylo-mastoid foramen and $0.25 \mathrm{ml}$. of the solution was injected. Now the direction of the needle was changed towards the outer canthus of the eye and the remaining $0.25 \mathrm{ml}$. of priscol was infiltrated along the course of the branches of the facial nerve as they fan over the malar bone.

After 6 injections, there was marked symptomatic improvement in the patient's condition. The epiphora and conjunctivitis disappeared. The patient appreciated the return of the lacity in the taut left upper lid, which had facilitated the blink reflex. The lid lagging was comparatively less marked. A further course of 6 injections was repeated and it significantly helped the patient in closing the left eye, although slight lagophthalmos persisted (Fig. 2).

The patient was followed after the termination of priscol therapy for a further period of 6 months. There was neither a recurrence of ectropion of the left lower lid nor any improvement in the lid closure function.

\section{COMMENTS}

Lagophthalmos in leprosy results from involvement of the motor branch of the facial nerve to the orbicularis oculi muscle either isolated or as a part of more extensive degeneration of the peripheral branches of the nerve. This degeneration of the nerve has a close relationship with vascular constriction generally manifested by the disease. The choice of priscol in prevention of degeneration of the nerve or its regeneration is obvious, as it has a local vasodilatory action and thus it improves the 
blood supply of the ischaemic nerve bundles (Mathur et al., 1966). Systemic administration of priscol has no value in the treatment of lagophthalmos. The present patient received as many as 18 intraneural injections in the upper limbs resulting in improvements in the degrees of deformities but no improvement was noted in his lid closure activity. Therefore local priscol therapy was attempted for the correction of the lagophthalmos.

It is evident from the foregoing case report that injections of priscol in the neighbourhood of the main facial nerve have improved function of the eye lids and cosmetic appearance of the patient, the patient's annoying epiphora disappeared and he could close the lids to a greater extent. The residual lagophthalmos in the present patient can be explained as irreparable damage done by the prolonged ischaemia caused by the long-standing disease. One may, therefore, expect complete recovery in a case of peripheral facial palsy where priscol therapy is instituted without allowing any time for paraneural or interneural fibroblastic proliferation, which in turn results in greater vasoconstriction and ultimate irreparable nerve degeneration.

Recently authors (Nema et al., 1967) have studied the topical effect of priscol in nonleprotic facial palsies of less than one year of duration where $B_{1}$ and $B_{12}$ therapy failed to be effective. The experience gained in the treatment of such patients is sufficient to conclude that improvement is more rapid and recovery of paralysis is more complete if priscol is locally administered in the neighbourhood of the facial nerve without losing much valuable time. It is, however, suggested that all patients of paralytic lagophthalmos should be subjected to local priscol injections before submitting to more intricate and less rewarding surgical procedures.

\section{SUMMARY}

Various available surgical techniques for the correction of lagophthalmos are reviewed. A medical treatment with local priscol injections in the neighbourhood of facial nerve was found to be encouraging in a patient of leprotic lagophthalmos. It has been suggested that all patients of paralytic lagophthalmos of recent onset should be subjected to priscol therapy before submitting them for intricate and less rewarding surgery.

\section{ACKNOWLEDGEMENTS}

Our grateful thanks are due to Principal K. N. Udupa for permitting us to publish the paper and for the encouragement received from Dr. K. S. Mehra, Professor of Ophthalmology.

\section{REFERENCES}

1. Doul (1937). Cited by Karat, S. (1965). Souv., 25th All India Ophthal. Conf., Madras, 73.

2. Gills, H. and millard, J. R. (1957). The Principles and Arts of Plastic Surgery, Vol. II, Butterworth, London, 608.

3. Glazenov, s. v. (1955). Vestn. Opth., 34, 25.

4. Loutfly (1937). Cited by Karat, S. (1965). Souv., 25th All India Ophthal. Conf., Madras, 73.

5. mathur, J. s. and SAxena, K. N. (1965). Lep. Rev., 36, 77 .

6. mathur, J. S. (1965). Souv., 10th Annual Conf., Aipha, 114.

7. MAthuR, J. S., SEhGAL, v. N. and RAO, N. S. (1966). Lep. Rev., 37, 249.

8. NEMA, H. v. (1967). Unpublished data. 